\title{
PicoGreen Dye
}

National Cancer Institute

\section{Source}

National Cancer Institute. PicoGreen Dye. NCI Thesaurus. Code C158432.

A proprietary dye for staining and quantitation of double-stranded DNA. It can selectively detect as little as $25 \mathrm{pg} / \mathrm{ml}$ of dsDNA in the presence of SsDNA, RNA, and free nucleotides. The assay is linear over three orders of magnitude and has little sequence dependence. 